\title{
Clustering Kruger National Park visitors based on interpretation
}

\author{
E. Botha ${ }^{a *} ;$ M. Saayman ${ }^{b}$ and M. Kruger ${ }^{b}$ \\ ${ }^{a}$ Department of Entrepreneurship, Supply Chain, Transport, Tourism and Logistics Management; \\ School for Public and Operations Management; University of South Africa; \\ P O Box 392; Muckleneuk Ridge; Pretoria; 0003; South Africa \\ ${ }^{\mathrm{b}}$ Tourism Research in Economic, Environs and Society; Faculty of Economic and Management Sciences; \\ North West University; Potchefstroom; South Africa \\ *To whom all correspondence should be addressed \\ vlogge@unisa.ac.za
}

\begin{abstract}
Interpretation is considered to be an important educational tool that not only addresses visitors' expectations but also contributes to national parks' conservation purposes. This study segmented the Kruger National Park's visitors based on expected interpretation services and revealed four clusters that differed based on their expected and experienced interpretation services as well as their motivational aspects. This study's distinct contribution is the alternative segmentation approach which revealed the viability of the expected interpretation variable to use for ecotourism segmentation purposes. This study not only assists the Kruger National Park to appropriately address interpretation services but also aids other ecotourism destinations.
\end{abstract}

\section{Introduction}

National parks' main resource of attraction is the environment (Said, Jaddil \& Ayob, 2009) and eco-tourists to national parks are interested in learning about and experiencing the environment (Jurdana, 2009; Kang \& Gretzel, 2012; Shultis \& Way, 2006). As a result, ecotourism destinations such as national parks include an interpretation experience (Kara, Deniz, Kilicaslan \& Polat, 2011) as part of ecotourism management to address the expectations of visitors (Saayman, 2009). It is therefore not surprising that Ham and Weiler (2007) found that interpretation influenced visitors' park experience more positively than noninterpretation services like accommodation or restroom facilities. Consequently, interpretation aids in attracting more visitors, increasing sales (Ham, Housego \& Weiler, 2005) and subsequently leads to higher revenue (Eagles, 2014). Interpretation can thus address park budget constraints as it is considered to be a successful park management technique (Reisinger \& Steiner, 2006; Wearing \& Neil, 2009).

To plan for interpretation it is imperative to understand the profile of the visitors since decisions for interpretation development are made from the visitor's point of view (Ham et al., 2005). Tourism marketing literature argues that people differ and can therefore be regarded as different markets with different needs (Dolnicar, 2008) that motivate certain behaviour (Getz, 2013). Hence the importance of market segmentation to identify profiles of visitors. One aspect of visitor profiles are the socio-demographic characteristics of the visitors and determine how the interpretation should be organised (i.e. the theme and type of media to communicate the theme) (Frauman, 2010) or adapted on the spot (Rabotić, 2010). Socio-demographic characteristics not only can assist in the development of interpretation but may also in turn explain the way tourists experience and regard satisfaction with services (Ham \& Weiler, 2007). An interpretation programme developed according to the visitors' profile in turn fulfils visitors' expectations, influences tourist satisfaction and future visitation behaviour (Lee, 2009), increases the possibility of spending more time at the destination (De Rojas \& Camarero, 2008) and thus increases the revenue needed for conservation which can also assist in greater sustainability.

The Kruger National Park, which is the focus of this study, is the largest national park of the 21 national parks managed by SANParks and is considered to be their flagship park. However, even though Engelbrecht, Kruger and Saayman (2014) found that there is a gap between what the visitors to the Kruger National Park expected and experienced with regards to interpretation and education activities (part of interpretation), the focus on interpretation is less important in the strategic plan for commercialisation, which forms a significant part of their ecotourism pillar (SANParks, 2013), aiming to deal with budget constraints and continual financial sustainability (SANParks, 2013, 2014). In reality, interpretation is not a focal point for SANParks whatsoever but seems to be the initiative of different park managers under SANParks. Planning for interpretation is therefore not considered to be a priority in SANParks and especially not in the Kruger National Park.

The aim of this study is therefore to identify market segments of the Kruger National Park based on expected interpretation services and then to differentiate the segments based on socio-demographic and behavioural characteristics, expected and experienced interpretation services as well as motivations to visit the park. Furthermore this study also has a unique contribution by identifying differences between the segments based on their experience with the interpretation services as 
to consequently reduce the gap between what interpretation services will be and what they should be (Ham \& Weiler, 2006). This is because tourists' needs, expectations and interests are directly related to the quality of the interpretation and an indication of a national park's competitiveness (Rabotić, 2010).

\section{Literature review}

Planning for interpretation involves eight steps: (1) interpretive inventory; (2) interpretive goals; (3) identify visitors; (4) determine outcomes of goals; (5) develop themes; (6) develop media matrices; (7) implementation plan; and (8) evaluation process (Ham et al., 2005). To understand this process, the following sections will focus on what is meant by interpretation and specifically consider the process involved for identifying visitors (i.e. market segmentation) for interpretation and literature on segmentation within interpretation.

\section{Interpretation}

For the purpose of this study the definition stated by Tilden (1977), the father of interpretation, will be used. He defined interpretation as "an educational activity which aims to reveal meanings and relationships through the use of original objects, by first hand experiences, and illustrative media, rather than simply to communicate factual information" (Tilden, 1977:8). Tilden (1977) was consequently the first author to identify different types of interpretation, namely attended (i.e. person-to-person contact like game drives or educational talks) and unattended (no personal contact like educational displays and exhibits). Tilden's classification closely corresponds with Ward and Wilkinson's (2006) personal and impersonal interpretation. Other authors, however, have given more complex classifications like Kuo (2002) and Stewart, Hayward, Devlin and Kirby (1998). Stewart et al. (1998) classified interpretation into primary(readably identified as interpretation like interpretation centres), secondary- and tertiary interpretation (which both respectively have an impact on the experience with primary interpretation like written commentaries at an activity and advertisement of interpretation). Stewart et al.'s (1998) distinction correlates well with Kuo's (2002) classification of hard (i.e. secondary and tertiary interpretation) and soft interpretation (i.e. primary interpretation).

Irrespective of which classification to use, interpretation is specifically used for successful and sustainable management of eco-tourism destinations such as national parks (Jurdana, 2009; Wearing \& Neil, 2009). These interpretation services in national parks are usually in the form of game drives, guided walks or educational talks to name but a few. The reason that interpretation is necessary for effective park management is that interpretation can be regarded as the link between conservation and tourism management of a national park as indicated in Figure 1.

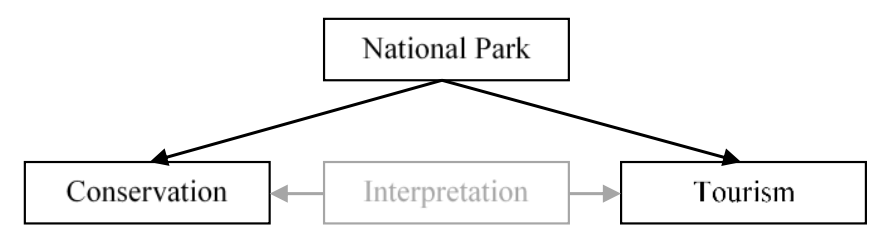

Figure 1: Interpretation's link between the tourism and conservation functions of a national park

Source: Author's own figure based on the literature review

The main objective of national parks in South Africa is to conserve the environment to be retained in its natural state (National Parks Act 57 of 1976). Interpretation, as depicted in Figure 1, assists with conservation management by broadening visitors' knowledge about the place they are visiting by revealing the significance of their experience and assisting their understanding (Periera, 2005; Reisinger \& Steiner, 2006). It is thus not surprising that interpretation is regarded as part of the ecotourism experience (Kara et al., 2011). This, in turn, leads to the protection of the environment since the understanding creates a respect and concern for species (Ballantyne, Packer \& Sutherland, 2011) supporting nature conservation work and protecting endangered species (Zeppel \& Muloin, 2008). Understanding the conservation philosophy of national parks therefore determines the overall direction of the interpretation services to offer (Ward \& Wilkinson, 2006). As illustrated in Figure 1 , interpretation is also a means of managing visitors' educational expectations (Saayman, 2009) since visitors to national parks are well educated and expect information-rich experiences (Jurdana, 2009). Interpretation as a result adds value to the tourism experience (Ballantyne et al., 2011; Ham $\&$ Weiler, 2006) and leads to a range of other benefits such as increased satisfaction, loyalty, increased purchasing, increased revenue, visitors spending more time at the national park, encouraging other visitors to visit the park, and providing positive word-of-mouth referrals for the park (De Rojas \& Camarero, 2008; Engelbrecht et al., 2014; Hwang, Lee \& Chen., 2005; Lee, 2009; Zeppel \& Muloin, 2008). National parks, and especially the Kruger National Park, should therefore place more emphasis on delivering interpretation services given that interpretation will not only benefit the park's tourism function but the additional revenue (and other benefits) will also enable the park to fulfil its main purpose of conserving the environment.

However Ham et al. (2005) caution that the visitor is a critical element to the delivery and outcomes of interpretation. Kuo (2002) suggests that, at the planning stage for an effective interpretation programme, management needs to research visitor demographics since each visitor has unique interests, needs, expectations, preferences and purpose for visiting. For that reason, it is important to take the time and effort to achieve a clear understanding of who the interpretation visitors are, why they visit, and the experiences they seek and enjoy (Ham et al., 2005). Hence the importance of market segmentation based on interpretation expectations. 
Market segmentation based on interpretation as a segmentation variable

Market segmentation is a process of dividing a market into distinct subset of customers with common needs and/or characteristics (Schiffman \& Kanuk, 2004). Segmenting a market is, however, only the first step of a three-phase marketing strategy. After segmenting a market into different segments, one or more target markets (step two) are identified and a specific marketing mix for each target market is designed where after the product is positioned for each of these target markets (Dolnicar, Grün, Leisch \& Schmidt, 2014). Profiling customers is therefore crucial for policymakers, managers and marketing analysts since identifying homogeneous markets is an essential step for both planning and developing strategies (D'Urso, De Giovanni, Disegna \& Massari, 2013). Focusing only on one or two target markets increases the chances of marketing success and improves the overall survival and profitability of the business (Dolnicar, Kaiser, Lazarevski \& Leisch, 2012).

Segmentation can be conducted using various different bases such as demographics (e.g. age, gender, marital status); sociodemographics (e.g. education, household composition); socio-economics (e.g. income, employment); socio-cultural (e.g. family life cycle, social class); geographical (e.g. place of origin); psychological (e.g. personality, perceptions, attitudes); psychographics (e.g. activities-interests-opinions, beliefs, values, lifestyles); benefits (e.g. what consumers want, motivations to travel); product-related (e.g. special interest travellers); and user-related (e.g. rate of usage, awareness, brand loyalty) (Getz, 2013; Morrison, 2013). The basic premise of market segmentation, depending on the circumstances, is that some customers (i.e. segments) are similar to each other and, in turn, different from other customers (i.e. segments). It is therefore possible to segment a market into different groups based on only one criterion or a combination, to delimit target markets (Getz, 2013; Morrison, 2013). The segmentation process therefore involves selecting a variable or a combination of variables from the segment bases mentioned earlier that best differentiate between customers (Nykiel, 2007). This variable(s) is/are known as the active variable(s) (Dillon \& Mukerjee, 2006). Active and other non-active variables can then further be used to characterise or differentiate between the segments (Dillon \& Mukerjee, 2006; D’Urso et al., 2013) and appropriately profile customers.

This study makes use of cluster analysis, which will be discussed at a later stage, to determine clusters (i.e. segments) for the Kruger National Park based on their expectations regarding interpretation services. One of the criticisms that researchers should address for cluster analysis is the selection of active variables. This is because (i) the technique has no means of differentiating relevant from irrelevant variables and (ii) that the cluster solution is dependent upon the variables (Hair, Black, Babin \& Anderson, 2010). A strong conceptual support is therefore needed and researchers are recommended to select the active variables with the research goal as criterion (Hair et al., 2010). Hence it is necessary to consult previous interpretation research to identify relevant segmentation variables.

Upon consulting previous research Ward and Wilkinson (2006) explain that both socio-demographic and behavioural characteristics are useful in planning for interpretation. Socio-demographic characteristics help with deciding which facilities, programmes, topics and recreational opportunities should be provided and motivations (i.e. behavioural characteristics) are useful in preparing programmes that meet and satisfy visitors' expectations (Ward \& Wilkinson, 2006). Segmenting interpretation markets by identifying their age gives destination managers an idea of prior knowledge (e.g. older individuals might have greater prior knowledge than younger individuals) (Peake, Innes \& Dyer, 2009) and attitudes towards animals in captivity (e.g. older individuals might know more about conservation and have more affection towards certain conservation aspects) (Lucas \& Ross, 2005) for developing interpretation programmes. Determining visitors' education level, on the other hand, may also assist in developing interpretation to influence their attitudes toward conservation (Lucas \& Ross, 2005). Other variables or visitor characteristics like language or nationality determine the language in which interpretation should be presented (Saipradist \& Staiff, 2007) or how the interpretation will be consumed (Prentice \& Anderson, 2007). If visitors are motivated to spend time with family and friends the interpretation programme can be designed to capitalise on this by evoking powerful memories and making lasting impressions (Ballantyne et al., 2011). Determining their interpretation expectations or motivations allows managers to cater for their skill and knowledge (Eagles, 2004) or making improvements to interpretation services (Lee, Jeon \& Kim, 2011). Particularly interesting from the table above is that little research has been conducted on market segmentation within the interpretation context except for Chen, Hwang and Lee (2006). The rest of the studies only identified certain differences between interpretation and one or more socio-demographic and behavioural characteristic but the aim was not to identify market segments for interpretation or use it as a segmentation base.

Even though little research refers to product-related segmentation for interpretation, it is a credible segmentation base for segmenting ecotourists. According to Getz (2013) and Morrison (2013) product-related segmentation refers to segmenting visitors based on specific interests. One of the special interest tourism categories is ecotourism of which the visitors (i.e. ecotourists) are characterised as highly educated and interested in learning about the environment (Jurdana, 2009; Kang \& Gretzel, 2012; Shultis \& Way, 2006) and motivated to visit ecotourism destinations to escape their daily lives (Chan \& Baum, 2007). In view of the latter and considering that national parks deliver interpretation services (Kara et al., 2011) to address the expectations of visitors (Saayman, 2009), segmenting visitors based on their expectations of interpretation services is a convincing active variable. To date however, little research has attempted to segment visitors within the interpretation context. Research also falls short in using expected interpretation as a variable for product-related (i.e. ecotourism) segmentation. This 
study will therefore be the first of its kind in addressing both the gaps of segmentation within interpretation as well as using expected interpretation variables to segment markets.

Interpretation assists in two ways: (i) interpretation allows visitors to understand and appreciate the environment they are visiting and hence assist conservation, and (ii) interpretation is part of addressing tourists' expectations of learning and thus supports the park's tourism function and, in turn, increases the revenue for conservation. To achieve these goals, planning for interpretation necessitates that the Kruger National Park should segment the market. Segmentation can specifically be done on the basis of visitors' expectations for interpretation as a type of product-related segmentation base. This will specifically identify possible markets for interpretation services where non-active variables can be used to further profile visitors and position interpretation services accordingly.

\section{Method of research}

The method of research conducted in this study is discussed under the following headings: (i) survey design; (ii) survey implementation; and (iii) statistical analysis.

\section{Study design}

This research followed a quantitative research approach by means of a self-administered questionnaire to collect data from the visitors to the Kruger National Park.

Sections A to E were predominantly used for the purpose of this study by differentiating between interpretation market segments based on socio-demographic, behavioural and motivational variables. Section A pertained to demographic characteristic questions (mostly nominal and ordinal) of respondents in the Kruger National Park. Section B's questions related to expected and experienced interpretation services as well as behaviour intentions as a result of the interpretation services in the Kruger National Park. These questions were measured on Likert scales that complied with the sensitive aspect of good measurement (Zikmund, Babin, Carr \& Griffin, 2010) since: (i) the expected questions measured respondents' importance of the listed interpretation services (see Table 1); (ii) the experienced questions measured how well the interpretation services was experienced (see Table 1); (iii) the behavioural intentions questions measured respondents' level of agreement with the listed behavioural intentions (see Table 4).

To cover the breadth of the interpretation domain, the above questions also complied with content validity (Malhotra, 2007; Zikmund et al., 2010) since the questions were based on the following authors' work: Ballantyne, Packer and Hughes (2008); Ballantyne et al. (2011); De Rojas and Camarero (2008); Frauman and Norman (2004); Ham and Weiler (2007); Henker and Brown (2011); Hwang et al. (2005); Kuo (2002); Lee (2009); Lee and Balchin (1995); Lee, Lee, Kim and Mjelde (2010); Madin and Fenton (2004); Mitsche, Reino, Knox and Bauernfeind (2008); Orams
(1994;1996); Periera (2005); Powell and Ham (2008); Reisinger and Steiner (2006); Stewart et al. (1998); Ward and Wilkinson (2006); and Zeppel and Muloin (2008). By means of factor analysis (see Results), this study addresses construct validity by determining the classification of interpretation that are most consistent with the variables of Section B (Zikmund et al., 2010). The last aspect, reliability, was measured by means of the alpha coefficient: when $\alpha<0.6$ the scale is unreliable and indicates unsatisfactory internal consistency (Malhotra, 2007); $\alpha=0.6$ and 0.7 indicates fair reliability; $\alpha$ $=0.7$ to 0.8 indicates good reliability; and $\alpha=0.8$ to 0.95 indicates very good reliability (Zikmund et al., 2010).

Along with Section A, sections C to E were used to compare with section B's continuous variables. These sections captured information regarding respondents' spending habits, where they heard about the park, motivations to visit the park, preference of the Big 5 animals, and experience with noninterpretation services in the park. These questions included Likert scale, open ended as well as close ended categorical questions.

\section{Sampling and survey implementation}

The distribution of questionnaires was done in two phases to cover the whole park. Phase one (between 27 December 2011 and 3 January 2012 in the southern region) covered Satara, Skukuza, Lower Sabie, and Berg en Dal rest camps. Phase two (conducted in the northern region between 24 June and 2 July 2012) covered Olifants, Letaba, Mopani, Shingwedzi and Punda Maria rest camps. Fieldworkers were assigned for two days to a specific area within the rest camps and briefed beforehand on the goals and the content of the questionnaire. Fieldworkers distributed one questionnaire per overnight travelling group by explaining the purpose of the study to the potential respondent, voluntary participation and indicated that they may withdraw from the study at any moment.

Since only one questionnaire should be distributed per travelling group, the total of overnight visitors to the Kruger National Park for 2012 was divided by the average of people per travelling group (4) to calculate the population for sampling purposes. This resulted in a new population of $(N)$ 352949 (SANParks, 2012). A sample of $(n) 384$ is required for a population $(N)$ of 352949 tourists to the Kruger National Park with a $95 \%$ confidence level and a 5\% sampling error $[d$ is in other words expressed as (.05)] to validate analysis (Krejcie \& Morgan, 1970). After cleaning the data set (extreme outliers deleted) $n=687$ and hence was more than the required number of questionnaires to validate analysis.

\section{Statistical analysis}

Once the questionnaires were obtained, data were captured in Microsoft Excel and analysed by means of SPSS (SPSS, 2013). The analysis was done in three stages as discussed below:

Factor analyses were done in the first stage of the study to determine (i) the interpretation services that respondents 
expect from the Kruger National Park and to be used as one of the scenarios in cluster analysis (see second stage). Furthermore; factor analyses determined (ii) how respondents experienced these interpretation services at the Kruger National Park; and (iii) the motivations of respondents who visit the Kruger National Park that, along with the results of the expected interpretation factor analysis, the results of these factor analyses were used in stage three of data analysis to differentiate between different clusters. For all three of these factor analyses, the Bartlett's (1954) test of sphericity (i.e. $p$ $\leq .05$ ) and Kaiser-Meyer-Olkin (KMO) (Kaiser, 1974) measure of sampling adequacy (i.e. is a minimum of 0.6) was performed to determine whether a factor analysis could have been conducted on the relevant scales' data variables. To determine the smallest number of factors from the data variables, the pattern matrix of the principal axis factoring extraction technique was applied whereas the Kaiser Normalisation (eigenvalues above 1.0 or more) guided the decision on the number of factors retained. The decision of factor loadings for this study was based on the following guidelines: (i) factors are reliable when the average of the four largest loadings is greater than 0.60 or the three largest loadings are greater than 0.80 (Stevens, 2009); (ii) factors with only a few low loadings can be interpreted if the sample size is at least 300 to indicate a reliable factor (Guadagnoli \& Velicer, 1988); and (iii) for a sample of 600, the loadings of variables should at least be 0.210 (Stevens, 2009). Where an item cross-loaded on two factors the item was categorised under the relevant factor guided by literature where the Oblimin oblique rotation technique assisted in factor interpretation. Only reliability coefficients above 0.6 were considered as acceptable for the study since coefficients below 0.6 indicate poor reliability of the scale and unsatisfactory internal consistency (Malhotra, 2007; Zikmund et al., 2010). Inter-item correlations were additionally calculated as another reliability measure which, recommended by Briggs and Cheek (1986), should be between 0.2 and 0.4 .

Secondly, cluster analysis was performed on several expected interpretation variables. The purpose of clustering methods is to maximise homogeneity of observations within a cluster or segment and simultaneously maximise heterogeneity between clusters or segments (Hair et al., 2010; Zikmund et $a l ., 2010)$. As discussed earlier, the expected interpretation variables were chosen specifically to segment ecotourism visitors based on product-related segmentation. Since the selection of variables for cluster analysis is a crucial consideration, it was necessary to compare three different scenarios to select the correct set of variables for cluster analysis. These three scenarios were identified as: (1) raw data (all 24 expected interpretation variables) since Dolnicar and Grün (2008) recommend the use of raw data as the interpretation of segments in factor-clustering is based on transformed information and thus questionable; (2) factors (identified from the expected interpretation factor analysis, see Table 1) which is a typical procedure in the preprocessing of cluster analysis in tourism literature; and (3) surrogate variables that represent the original variables in a factor and interpreted in terms of the original factors (Hair et al., 2010; Malhotra, 2007) [variables with the highest loadings on each factor in the factor analysis (these variables were the least correlated) as well as the variable "Informed staff who can handle queries regarding the interpretation of the park" which was removed from the factor analysis and regarded as a factor on its own]. Outliers were deleted from the three scenarios' datasets (Hair et al., 2010) and coefficient of variance $\left(\mathrm{C}_{\mathrm{v}}\right)$ was calculated for all three scenarios to determine which scenario has the least variability. The variability along with the multicollinearity assumption guided the decision as to which scenario should be used for cluster analysis. It was therefore decided to use the surrogate variables since these variables were the least correlated, variable and addressed multicollinearity.

The surrogate variables were then cluster analysed both hierarchically and non-hierarchically. Since the nonhierarchical procedure requires the researcher to indicate the number of clusters to be retained (Schmidt \& Hollensen, 2006; Sharma \& Kumar, 2006) the initial clustering solution from the hierarchical procedure was then specified in the nonhierarchical procedure (Hair et al., 2010; Malhotra, 2007). The hierarchical and non-hierarchical procedures typically used in tourism research (Füller \& Matzler, 2008) are Ward's [clustering technique aims at minimising inter-cluster variance (Malhotra, 2007; Schmidt \& Hollensen, 2006)] and K-means clustering techniques [maximises within-cluster homogeneity (Hair et al., 2010) and identifies clusters of nearly equal sizes (Sharma \& Kumar, 2006)]. The K-means clustering technique selects temporary $k$ centres based on the number of clusters specified from the Ward's clustering technique and partitions observations to those centres (Hair et al., 2010; Malhotra, 2007). The cluster solution was validated to assure the cluster solution is representative of the general population and generalisable to other objects (Hair et al., 2010) by running the analysis on sorted cases (in this case by Age) as the order of cases can affect the cluster membership (Hair et al., 2010:557; Malhotra, 2007). Only $18 \%$ of the second cluster analysis' cases were not clustered together as they did with the first cluster analysis and thus indicate that the cluster solution is stable (Hair et al., 2010).

Thirdly, both chi-square tests and ANOVAs were calculated to investigate whether any significant differences exist between the clusters based on active (i.e. the three surrogate variables) and non-active variables (i.e. variables not used for cluster analysis) like socio-demographic and behavioural characteristics, experienced interpretation and motivational aspects. Chi square tests were used to identify differences between two or more categorical variables (Pallant, 2011) and ANOVAs to investigate statistical differences of mean values between groups (Pallant, 2011). Tukey's Honestly Significant Difference test was additionally used as a posthoc test (Pallant, 2011). The effect sizes were also calculated [phi $(\Phi)$ coefficient for chi square tests and $d$-value for ANOVAs] to determine whether marginal differences exist. According to Cohen (1988) when $\Phi$-value or $d$-value is 0.2 it indicates a small effect (research ought to be replicated to determine whether there is an effect or if the result is practically non-significant); $d=0.5$ indicates a medium effect (might point towards practical significance); and if $d=0.8$ 
shows practical significance (practical importance) (Steyn, 2000).

\section{Results}

The following section examines the results obtained from the factor analyses, cluster analyses, chi-square tests as well as the results from the ANOVAs.

\section{Results of the factor analyses}

As previously indicated, three factor analyses were conducted for this study: (i) expected interpretation services, (ii) experiences with the interpretation services of the park, and the (iii) motivations of respondents to visit the park. These factors were then used for further analyses to profile the market segments identified in the second and third stage of analyses. The discussions of the results follow in the sections below.

\section{Factor analyses on expectations and experiences with interpretation services}

The first round of factor analysis revealed that one variable, informed staff who can handle queries regarding the interpretation of the park did not load under the correct factor as literature indicates (i.e. primary interpretation) and it was therefore decided to exclude it from the second round of analysis and regard it as a factor on its own. The principal axis factoring analysis using an Oblimin oblique rotation with Kaiser normalisation on the remaining 23 variables identified two factors for expectations as well as experiences with interpretation services (see Table 2). Factor 1 was labelled Primary interpretation, Factor 2 Secondary interpretation and Factor 3, as previously indicated is Knowledgeable staff. The Bartlett's test revealed statistical significance $(p=0.001)$ and the KMO for sampling adequacy resulted in 0.941 and 0.931 respectively. Only eigenvalues above 1 were used which resulted in two factors that accounted for $56 \%$ and $50 \%$ respectively of the total variance explained. The average of all items contributing to a specific factor revealed factor scores that interpret the factor to the original five-point Likert scales respectively. All factors indicated very good convergent validity with Cronbach alphas above 0.8 and inter-item correlations of between 0.40 and 0.50 .
Table 1 indicates that respondents regard primary interpretation as very important (2.42) for a quality experience in the Kruger National Park. Secondary interpretation (1.74) as well as knowledgeable staff (1.74) are also very important, but marginally less important compared to primary interpretation. The experience with these factors revealed that secondary interpretation (2.39) was experienced well; however primary interpretation (2.92) and knowledgeable staff (3.13) were experienced moderately. Comparing the expectations with the experiences with these factors disclose that only secondary interpretation met the respondents' expectations (1.74) as they have indicated that they have experienced this factor satisfactorily (2.42) and that primary interpretation (2.42) and knowledgeable staff (1.74) however were not experienced according to the expectations of respondents since the mean values of the experienced scale reveal that both these factors were experienced moderately with 2.92 and 3.13 respectively.

\section{Factor analysis on motivations to visit the park}

A minimum of three factors were identified on the 12 motivation variables by the principal axis factoring analysis, using an Oblimin oblique rotation, with Kaiser normalisation and eigenvalues above 1 (see Table 2). Hence the total variance explained was 55\%. Factor 1 was labelled Special interest needs since these items refer to interests that ecotourism literature reveals for these visitors, Factor 2 Escape and Factor 3 Park facilities and value. The KMO for sampling adequacy resulted in 0.766 and the Bartlett's test revealed statistical significance $(p=0.001)$. The average of all items contributing to a specific factor revealed factor scores that interpret the factor to the original five-point Likert scale. All three factors indicated very good convergent validity with Cronbach alphas between 0.7 and 0.9 and interitem correlations of between 0.2 and 0.7. Respondents indicated that escape (4.26) is a very important motivation to visit the Kruger National Park. Even though park facilities and value (3.56) can be considered to be very important as well, this motivation differs marginally from special interest needs as an important (3.34) motivation to visit the park. 
Table 1: Factor analyses for expectations of - and experiences with interpretation services of the Kruger National Park

\begin{tabular}{|c|c|c|c|}
\hline Interpretation Expectations $^{\circ}$ & $\begin{array}{l}\text { Factor } \\
\text { loading }\end{array}$ & Interpretation Experience $^{\circ}$ & $\begin{array}{l}\text { Factor } \\
\text { loading }\end{array}$ \\
\hline Factor 1: Primary interpretation & & Factor 1: Primary interpretation & \\
\hline $\begin{array}{l}\text { Interpretation activities e.g. slide shows, informative } \\
\text { sessions and specialist talks }\end{array}$ & .825 & Geological and climatological displays & .821 \\
\hline Auditorium with nature videos & .780 & $\begin{array}{l}\text { Interpretation activities e.g. slide shows, informative } \\
\text { sessions and specialist talks }\end{array}$ & .817 \\
\hline Geological and climatological displays & .716 & Educational talks, activities and games for children & .810 \\
\hline Educational displays & .527 & Educational displays & .771 \\
\hline Educational talks, activities and games for children & .513 & $\begin{array}{l}\text { Information boards regarding the fauna/flora in the } \\
\text { park }\end{array}$ & .668 \\
\hline Information regarding the history of the park & .401 & Information regarding the history of the park & .656 \\
\hline Information boards regarding the fauna/flora in the park & .388 & Auditorium with nature videos & .637 \\
\hline $\begin{array}{l}\text { Lifelike examples of different animals, insects, birds and } \\
\text { trees with descriptive data }\end{array}$ & .366 & $\begin{array}{l}\text { Lifelike examples of different animals, insects, birds } \\
\text { and trees with descriptive data }\end{array}$ & .491 \\
\hline $\begin{array}{l}\text { Information centres and interpretation centres in specific } \\
\text { rest camps }\end{array}$ & .264 & $\begin{array}{l}\text { Identification of trees, e.g. nameplates or information } \\
\text { boards }\end{array}$ & .425 \\
\hline $\begin{array}{l}\text { Identification of trees, e.g. nameplates or information } \\
\text { boards }\end{array}$ & .234 & Authenticity of interpretation & .421 \\
\hline Authenticity of interpretation & .825 & $\begin{array}{l}\text { Information centres and interpretation centres in } \\
\text { specific rest camps }\end{array}$ & .407 \\
\hline Interactive field guides on game drives and guided walks & .780 & $\begin{array}{l}\text { Interactive field guides on game drives and guided } \\
\text { walks }\end{array}$ & .268 \\
\hline Mean value & 2.42 & Mean value & 2.92 \\
\hline Reliability coefficient & .91 & Reliability coefficient & .91 \\
\hline Average inter-item correlation & .45 & Average inter-item correlation & .44 \\
\hline \multicolumn{2}{|l|}{ Factor 2: Secondary interpretation } & \multicolumn{2}{|l|}{ Factor 2: Secondary interpretation } \\
\hline Clear directions to rest camps and picnic areas & .964 & Clear directions to rest camps and picnic areas & .886 \\
\hline Available route maps with descriptive information & .951 & Accessibility of the park & .829 \\
\hline Good layout of the park, rest camps and routes & .900 & Available route maps with descriptive information & .813 \\
\hline Accessibility of the park & .889 & Good layout of the park, rest camps and routes & .758 \\
\hline Enforcement of park rules and regulations & .764 & $\begin{array}{l}\text { Available books, brochures, information pamphlets } \\
\text { and park guides for animal, insects, birds and trees }\end{array}$ & .643 \\
\hline $\begin{array}{l}\text { Available books, brochures, information pamphlets and } \\
\text { park guides for animal, insects, birds and trees }\end{array}$ & .709 & $\begin{array}{l}\text { Information regarding interpretation in the park } \\
\text { available on the web }\end{array}$ & .457 \\
\hline $\begin{array}{l}\text { Information regarding interpretation in the park available } \\
\text { on the web }\end{array}$ & .626 & Lookout points in the park & .450 \\
\hline Lookout points in the park & .567 & Information boards with animal tracking & .429 \\
\hline $\begin{array}{l}\text { Marketing of the park and its wildlife as well as activities } \\
\text { on the web, in magazines, newspapers and on the radio }\end{array}$ & .523 & $\begin{array}{l}\text { Marketing of the park and its wildlife as well as } \\
\text { activities on the web, in magazines, newspapers and on } \\
\text { the radio }\end{array}$ & .385 \\
\hline Information boards with animal tracking & .515 & Enforcement of park rules and regulations & .358 \\
\hline Bird hides in the park & .324 & Bird hides in the park & .309 \\
\hline Mean value & 1.74 & Mean value & 2.42 \\
\hline Reliability coefficient & .91 & Reliability coefficient & .88 \\
\hline Average inter-item correlation & .50 & Average inter-item correlation & .40 \\
\hline Factor 3: Knowledgeable staff & & Factor 3: Knowledgeable staff & \\
\hline $\begin{array}{l}\text { Informed staff who can handle any queries concerning the } \\
\text { interpretation aspects in the park }\end{array}$ & .647 & $\begin{array}{l}\text { Informed staff who can handle any queries concerning } \\
\text { the interpretation aspects in the park }\end{array}$ & .630 \\
\hline Mean value & 1.74 & Mean value & 3.13 \\
\hline Total variance explained & $55.6 \%$ & Total variance explained & $49.5 \%$ \\
\hline
\end{tabular}


Table 2: Results of the factor analysis on the motivations of respondents to visit the Kruger National Park

\begin{tabular}{|c|c|c|c|c|}
\hline Motivations $^{\circ}$ & Factor loading & Mean value & $\begin{array}{l}\text { Reliability } \\
\text { coefficient }\end{array}$ & $\begin{array}{l}\text { Average inter-item } \\
\text { correlation }\end{array}$ \\
\hline Factor 1: Special interest needs & & 3.34 & .71 & .26 \\
\hline Primarily for educational reasons & .656 & & & \\
\hline To explore a new destination & .591 & & & \\
\hline To spend time with friends & .497 & & & \\
\hline For the benefit of my children & .405 & & & \\
\hline To photograph animals and plants & .349 & & & \\
\hline It is a spiritual experience & .295 & & & \\
\hline To see the Big 5 & .255 & & & \\
\hline Factor 2: Escape & & 4.26 & .83 & .71 \\
\hline To relax & .751 & & & \\
\hline To get away from my routine & .729 & & & \\
\hline Factor 3: Park facilities and value & & 3.56 & .72 & .47 \\
\hline The park has great accommodation and facilities & .750 & & & \\
\hline I am loyal to the park & .649 & & & \\
\hline It is value for money & .622 & & & \\
\hline Total variance explained & & \multicolumn{3}{|l|}{$54.8 \%$} \\
\hline
\end{tabular}

-Likert scale: 1 = Not at all important to 5 = Extremely important

\section{Results of the cluster analyses}

Given that this study made use of a conjoint hierarchical and non-hierarchical approach, the surrogate variables were first analysed by means of Ward's cluster analysis. The number of cluster solutions to pre-specify for the K-means cluster analysis was calculated by means of the percentage changes in heterogeneity from the coefficients obtained from the Ward's cluster analysis. This rule specifies that when large increases in heterogeneity occur in moving from one stage to the next, the prior cluster solution is selected because the new combination is joining quite different clusters (Hair et al., 2010). The Ward's clustering technique identified four clusters that should be retained for further K-means cluster analysis. The second round of cluster analysis thus revealed four cluster or segments of various sizes where segment 1 is $n=158,2$ is $n=429,3$ is $n=69$ and 4 is $n=31$. The differences between these segments are more clearly identifiable when ANOVAs are performed based on the active variable (i.e. expected surrogate interpretation variables) illustrated in Table 3.

Table 3: ANOVAs for expected interpretation

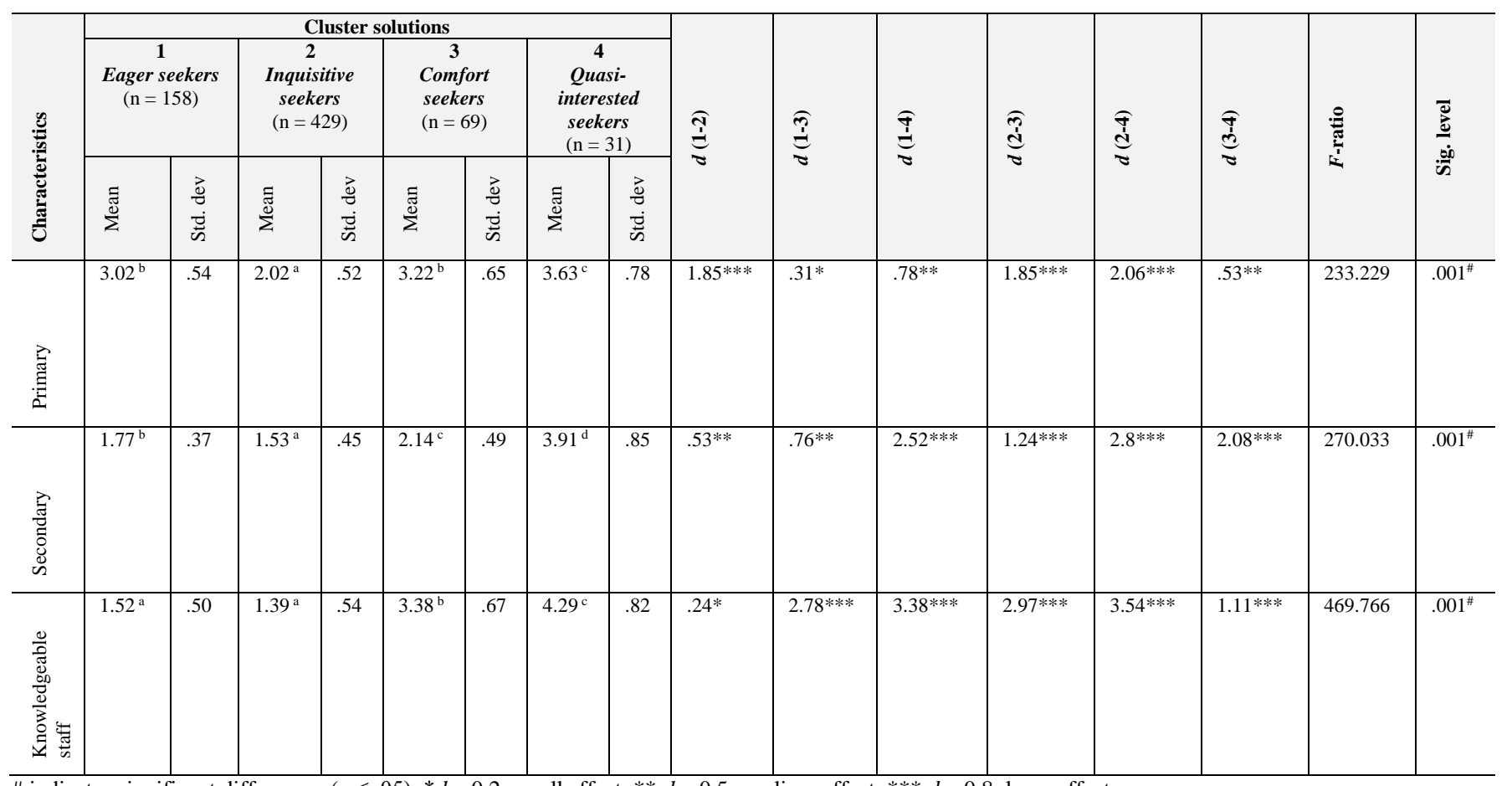

\# indicates significant differences $(p \leq .05) ; * d=0.2$ : small effect, $* * d=0.5$ : medium effect, $* * * d=0.8$ : large effect

${ }^{\circ}$ Measure from $1=$ Extremely important to $5=$ Not at all important

a differs from where $b, c$ and $d$ are indicated and vice versa 
Table 3 clearly indicates that the four market segments differ based on expected interpretation as indicated by the significance levels $(p \leq .05)$. Specifically referring to the mean values for the interpretation services of the market segments, it is clear why the relevant labels are provided to characterise these market segments. The second segment (discussed first for clarity reasons) indicated that primary (2.02), secondary interpretation services (1.53) and knowledgeable staff (1.39) are all very important to extremely important interpretation services for a quality experience to the park. Based on the importance on all three interpretation services and the fact that this segment is the largest $(n=429)$ this segment is labelled the Inquisitive seekers.

Segment one indicated that only secondary interpretation services (1.77) and knowledgeable staff (1.52) are very important for a quality experience at the Kruger National Park and regarded primary interpretation services (3.02) as neither very important nor less important. Even though this market has indicated the latter, the factor knowledgeable staff who can handle queries regarding the interpretation of the park indicates that this market is eager to learn when the interest arises and is therefore labelled as the Eager seekers. To be able to label segments 3 and 4 the motivations (which are discussed later) of these two markets were consulted in combination with their expected interpretation services. The third only regarded secondary interpretation service (2.14) as very important for a quality experience in the park. Considering that secondary interpretation refers to the layout, directions and accessibility of the park, to name but a few, as well as their strong motivation to visit the park for the park's facilities and value (more than special interest needs and less than escape) it can be assumed that this market places strong emphasis on comfort and unknowingly makes use of secondary interpretation to satisfy this need. Consequently, this market is labelled Comfort seekers. The last market segment is totally different from the previous markets seeing as they regard primary (3.63), secondary interpretation services (3.91) and knowledgeable staff (4.29) all as less important for a quality experience at the Kruger National Park. This market did, however, indicate that they regard special interest needs, which include education as a primary reason, as an important motivation to visit the park and can therefore not disregard them as a possible interpretation market. It is feasible that this market has, up to now, just not realised the importance of interpretation services to address their special interest needs (see Table 5) and hence labelled the Quasi-interested seekers. From the above discussion, it is clear that there are differences between the markets for interpretation services as identified by means of significant differences $(p \leq .05)$, medium to large practical significances as well as Tukey's post hoc tests.

The next section provides the results of the chi-square tests as well as the ANOVAs and should be consulted in combination to profile the different markets.

\section{Results of the Chi square tests and ANOVAs}

Chi-square tests identified only significant difference ( $p \leq$ .05) (with a small effect size) between the different market segments was based on home language. The Eager seekers (58\%), Inquisitive seekers (63\%) and Comfort seekers (66\%) predominantly speak Afrikaans whereas Quasi-interested seekers (52\%) speak English. Table 4 provides the results of the ANOVAs to furthermore indicate differences between the market segments.

The results in Table 4 indicate that the segments are homogeneous based on only socio-demographic and behavioural characteristics. Except for the Quasi-interested seeker (who are 43 years of age), all segments are 46 years of age, have a travel group of approximately 4, paid for approximately 3 people in the park, were exposed to a national park at 14 to 16 years of age, were 3 to 5 times a day visitor to the park, were 4 to 5 times an overnight visitor to the park, and spend approximately 8 nights at the park. The product-related [i.e. experienced secondary interpretation $(p$ $=.001)$ ] and benefit variables [i.e. special interest needs $(p=$ $.001)$, and Park facilities and value $(p=.004)]$ do, however, provide more significant differences $(p \leq .05)$ between the different segments.

Heterogeneity is also visible when comparing the expected interpretation services (see Table 4) with the experienced interpretation services for the different segments reveals the segments' degree of satisfaction with their experiences. The Inquisitive seekers regarded primary (2.02), secondary interpretation services (1.53) and knowledgeable staff as all very - to extremely important but only secondary interpretation met their expectations as they have experienced it well (2.34). Primary interpretation (2.89) as well as knowledgeable staff (3.08) did therefore not meet their expectations and suggests some room for improvement. The Eager seekers, however, expect that secondary interpretation (1.77) as well as knowledgeable staff (1.52) to be very important interpretation services for an experience in the park but only secondary interpretation met their expectations since the experience thereof was rated good (2.47) and knowledgeable staff as fairly experienced (3.11). Primary interpretation is neither important nor less important (3.02) for the Eager seekers and experienced it as fair (2.93). The Comfort seekers, however, only considered secondary interpretation (2.14) as very important but experienced it moderately (2.59). Primary interpretation (3.22) and knowledgeable staff (3.38) were considered neither important nor less important, but were experienced moderately (3.02 and 3.39 respectively). The Quasi-interested seekers considered all the interpretation services as less important (3.63, 3.91 and 4.29 respectively) but did experience these services moderately (3.00, 2.72 and 3.29 respectively) indicating that their experience was beyond their expectations. The only significant difference between the different segments in the Table 3 is identifiable at secondary experienced interpretation with small to medium effect sizes. 
Furthermore, all the segments regard escape as a very important motivation to visit the park (Inquisitive seekers = 4.33; Eager seekers $=4.29$; Comfort seekers $=4.12$; Quasi interested seekers $=4.32$ ) and it is therefore not surprising that there are no significant differences between the segments based on this specific motivation. Significant differences as well as small to medium effect sizes between the segments are however noticeable at special interest needs and park facilities and value as motivations to visit the park. Between the four segments the Comfort seekers placed less importance (2.99) on special interest needs than the other segments (Inquisitive seekers $=3.44 ;$ Eager seekers $=3.21 ;$ Quasiinterested seekers $=3.38)$ as well as with park facilities and value (3.20 compared to the Inquisitive seekers with 3.64; Eager seekers with 3.45 and the Quasi-interested seekers with 3.59).

\section{Table 4: ANOVA results for the Kruger National Park's interpretation segments}

\begin{tabular}{|c|c|c|c|c|c|c|c|c|c|c|c|c|c|c|c|c|}
\hline \multirow[t]{3}{*}{ Characteristics } & \multicolumn{8}{|c|}{ Cluster solutions } & \multirow{3}{*}{$\stackrel{\overbrace{}}{\stackrel{\overbrace{}}{ٌ}}$} & \multirow{3}{*}{$\stackrel{\overbrace ?}{\stackrel{?}{2}}$} & \multirow{3}{*}{$\underbrace{\stackrel{f}{I}}_{0}$} & \multirow{3}{*}{ 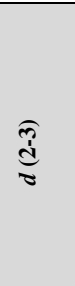 } & \multirow{3}{*}{ 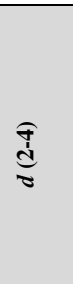 } & \multirow{3}{*}{$\begin{array}{c}\text { fं } \\
\stackrel{0}{\sigma}\end{array}$} & \multirow{3}{*}{ 䒿 } & \multirow{3}{*}{$\frac{\bar{d}}{\dot{0}}$} \\
\hline & \multicolumn{2}{|c|}{$\begin{array}{c}1 \\
\text { Eager seekers } \\
(\mathrm{n}=158)\end{array}$} & \multicolumn{2}{|c|}{$\begin{array}{c}2 \\
\text { Inquisitive } \\
\text { seekers } \\
(\mathrm{n}=429)\end{array}$} & \multicolumn{2}{|c|}{$\begin{array}{c}\mathbf{3} \\
\text { Comfort } \\
\text { seekers } \\
(\mathrm{n}=69)\end{array}$} & \multicolumn{2}{|c|}{$\begin{array}{c}4 \\
\text { Quasi- } \\
\text { interested } \\
\text { seekers } \\
(\mathrm{n}=31) \\
\end{array}$} & & & & & & & & \\
\hline & $\stackrel{\widetilde{\Xi}}{\stackrel{J}{\Sigma}^{2}}$ & $\begin{array}{l}\vec{z} \\
\dot{z} \\
\dot{z} \\
\text { in }\end{array}$ & $\stackrel{\Xi}{\sum_{\Sigma}^{ \pm}}$ & 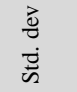 & $\stackrel{\varpi}{\Sigma}^{\Xi}$ & 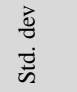 & $\stackrel{\Xi}{\Sigma}$ & $\begin{array}{l}\overrightarrow{0} \\
\dot{0} \\
\vec{D} \\
\dot{n}\end{array}$ & & & & & & & & \\
\hline \multicolumn{17}{|l|}{ Socio-demographics } \\
\hline Average age & 46 & 13.55 & 46 & 12.48 & 46 & 11.49 & 43 & 12.62 & 0 & 0 & $.22 *$ & 0 & $.24 *$ & $.24 *$ & .637 & .591 \\
\hline Average travel group & 4.14 & 2.68 & 4.15 & 2.42 & 4.57 & 3.88 & 4.40 & 2.57 & 0 & .11 & .10 & .12 & .10 & .04 & .571 & .635 \\
\hline Average people paid for & 3.00 & 1.80 & 3.24 & 1.75 & 3.14 & 1.67 & 2.83 & 1.69 & .13 & .08 & .09 & .06 & $.23 *$ & $.18^{*}$ & 1.090 & .353 \\
\hline $\begin{array}{l}\text { Average age exposed to a } \\
\text { park }\end{array}$ & 15.82 & 12.86 & 13.88 & 11.40 & 13.89 & 11.12 & 15.62 & 11.16 & .15 & .15 & .02 & 0 & .15 & .16 & 1.129 & .336 \\
\hline \multicolumn{17}{|l|}{ Behaviour $^{\circ}$} \\
\hline $\begin{array}{l}\text { Average time as a day } \\
\text { visitor }\end{array}$ & 2.61 & 5.04 & 3.55 & 8.17 & 2.85 & 5.89 & 5.00 & 9.68 & .12 & .04 & $.25 *$ & .09 & .15 & $.22 *$ & .439 & .724 \\
\hline $\begin{array}{l}\text { Average time as an } \\
\text { overnight visitor }\end{array}$ & 3.96 & 3.63 & 4.75 & 6.53 & 4.33 & 4.38 & 4.96 & 7.26 & .12 & .08 & .14 & .06 & .03 & .09 & .677 & .567 \\
\hline Average nights overnight & 7.75 & 7.31 & 8.27 & 8.40 & 7.65 & 5.18 & 7.75 & 6.08 & .06 & .01 & 0 & .07 & .06 & .02 & .255 & .858 \\
\hline \multicolumn{17}{|c|}{ Product-related ${ }^{\circ}$ : experienced interpretation } \\
\hline Primary & 2.93 & .61 & 2.89 & .69 & 3.02 & .54 & 3.00 & .61 & .06 & .15 & .11 & $.19^{*}$ & .16 & .03 & .995 & .395 \\
\hline Secondary & $2.47^{\mathrm{ab}}$ & .58 & $2.34^{\mathrm{a}}$ & .60 & $2.59^{\mathrm{b}}$ & .55 & $2.72^{\mathrm{b}}$ & .74 & $.22 *$ & $.21 *$ & $.34 *$ & $.42 *$ & $.51 * *$ & $.18^{*}$ & 6.839 & $.001^{\#}$ \\
\hline Knowledgeable staff & 3.11 & 1.07 & 3.08 & 1.10 & 3.39 & .89 & 3.29 & 1.05 & .03 & $26^{*}$ & .17 & $.28^{*}$ & $.19^{*}$ & .10 & 1.649 & .177 \\
\hline \multicolumn{17}{|c|}{ Benefits : motivations to visit the park } \\
\hline Special interest needs & $3.21^{\mathrm{ab}}$ & .78 & $3.44^{\mathrm{b}}$ & .82 & $2.99^{\mathrm{a}}$ & .77 & $3.38^{\mathrm{b}}$ & .77 & $.28 *$ & $.28^{*}$ & $.22 *$ & $.55^{* *}$ & .07 & $.51^{* *}$ & 7.440 & $.001^{\#}$ \\
\hline Escape & 4.29 & 1.03 & 4.33 & .98 & 4.12 & 1.04 & 4.32 & .72 & .04 & .16 & .03 & $.20 *$ & .01 & $.19^{*}$ & .886 & .448 \\
\hline Park facilities and value & $3.45^{\mathrm{ab}}$ & .98 & $3.64^{b}$ & .98 & $3.20^{\mathrm{a}}$ & .96 & $3.59^{\mathrm{ab}}$ & .91 & .19 & $.26^{*}$ & .14 & $.45^{*}$ & .05 & .41 & 4.424 & $.004^{\#}$ \\
\hline
\end{tabular}

-Likert scales: Experience: Measured from 1=Excellent to 5=Very poor; Expectations: Measured from $1=$ Not at all important to $5=$ Extremely important; Behaviour: $1=$ Strongly disagree to $5=$ Strongly agree; Motivations: $1=$ Not at all important to $5=$ Extremely important

$\#$ indicates significant differences $(\mathrm{p} \leq .05) ; * \mathrm{~d}=0.2$ : small effect, $* * \mathrm{~d}=0.5$ : medium effect, $* * * \mathrm{~d}=0.8$ : large effect;

a (in row) differs from where $b$ and $c$ are indicated

\section{Findings and implications}

The following findings and implications for this study can be deduced from the results discussed in the previous section.

The first finding of this study confirms that interpretation services are important for a quality experience in an ecotourism destination such as the Kruger National Park. However, there is a gap between the expected and experienced interpretation services which confirms Engelbrecht et al.'s (2014) study with regards to a difference between expectations and experiences of interpretation services in the park. This finding also confirms Lee, Lee, Mjelde, Scott and Kim's (2009) as well as Lee et al.'s (2010) suggestion that interpretation will increasingly play an important role in managing as well as enhancing satisfaction of ecotourism experiences. The three interpretation factors (see Table 1) identified as very important for a quality experience at the Kruger National Park were primary, secondary interpretation services and knowledgeable staff. These interpretation services correspond with Stewart et al.'s (1998) primary and secondary interpretation (a combination of secondary and tertiary interpretation). A third factor, however, was also identified from the factor analysis, namely knowledgeable staff. This is not surprising since Jurdana (2009) explains that to manage an ecotourism destination successfully, staff should have knowledge of communication and interpretation relating to natural and cultural heritage. The tourism industry is a service industry and, as a result, staff's expertise plays an important role in service delivery which once again highlights the importance of knowledge and training of staff. The experiences (see Table 1) with interpretation should also be discussed as an extension to this finding. Results indicate that only secondary interpretation met the respondents' expectations and that primary interpretation and knowledgeable staff were only moderately experienced. The latter suggests that the current interpretation services of the park are not sufficient to satisfy visitors' expectations and it is strongly recommended that the gap between expectations and experiences should be addressed. Considering the fact that all interpretation services are seen as very important for a quality experience in the park and only secondary interpretation met visitors' expectations, more emphasis should be placed on planning 
for primary interpretation and knowledgeable staff (which represents service quality and a requirement for the tourism industry) as these two factors were only experienced moderately.

The second finding of this study is that respondents indicated that there are common motives to visit the park. From the most important to the least important the motives are escape (4.26), park facilities and value (3.56) and special interest needs (3.34). The importance of escape and park facilities and value to visit the park correspond with previous research by Chan and Baum (2007) and Kruger, Saayman and Hermann (2014) that identified escape as the most important motive to visit ecotourism destinations. This study, however, also identified a distinct motivation different from previous ecotourism motivational studies, namely special interest needs. Bearing in mind that this study was based on an ecotourism destination and specifically focused on the interpretation context, this is not an unexpected motive to identify. Many of the items (e.g. to see the Big 5, to photograph animals, primarily for educational reasons, and it is a spiritual experience) under this motivation associate well with ecotourism as well as with interpretation characteristics. Because motivations indicate the needs and desires of travel (Chan \& Baum, 2007) and that motivations can give an indication of tourists' participation intentions (Mehmetoglu \& Normann, 2013) the identification of these specific needs will assist the park with marketing approaches specifically in combination with interpretation services. Two of the markets identified in this study (see finding below), have strong motivational aspects that unconsciously correspond with interpretation services. Addressing the motivational aspects in combination with the relevant interpretation services that could address these motivations will therefore also assist interpretational goals as well.

The third and most distinct finding of this study is that four interpretation market segments were identified for the Kruger National Park based on expected interpretation services, namely Inquisitive seekers, Eager seekers, Comfort seekers and Quasi-interested seekers. This implies that there are different needs and expectations and different markets with regards to interpretation services. This furthermore indicates that expected interpretation can be regarded as a viable variable for segmentation purposes whereas any other type of variable not associated with interpretation would have not provided the same results. This confirms Hair et al.'s (2010) recommendation to select the variables for cluster analysis based on the goal of the study. The four segments derived from the expected interpretation services ranged from a market where all interpretation services are very important (Inquisitive seekers), only secondary interpretation and knowledgeable staff are very important (Eager seekers), to where only secondary interpretation is important (Comfort seekers) and no interpretation is regarded as important (Quasi-interested seekers). The fact that segments can be identified for interpretation services compares well with Chen et al.'s (2006) research which identified market segments for interpretation services. Since the dependent variables differed between the studies, this study's segments, however, differed significantly from Chen et al.'s (2006) study. At first glance the four segments for this study seem to be homogeneous markets as most of their characteristics coincide with one another and quite possible considering that visitors to the park can be defined as ecotourists with the same special interest requirements. However, a few differences between the market segments did occur that indicated heterogeneous markets. The only socio-demographic characteristic where significant differences were found was based on home language. The latter confirms previous research of Saipradist and Staiff's (2007) who found that language had an impact on how interpretation services were understood. This is an important aspect to keep in mind whilst planning for interpretation since more and more people with different home languages are travelling and visit ecotourism destinations. Other differences were especially identified based on interpretation expectations as well as motivations (see Tables 3 and 4).

The implications of these findings reveal that two interpretation strategies can be identified for the Kruger National Park. The first strategy is to focus on both the Inquisitive and Eager seekers as target markets for interpretation purposes as these two markets are the largest and demand a variety of interpretation services. These two markets did however exposed some dissatisfaction with primary and knowledgeable staff that should be addressed to gain revenue from these markets for conservation purposes. The second strategy's focus should be on the Comfort and Quasi-interested seekers which are the smallest markets and make use of interpretation as a means to an end or have not yet realised the effect of interpretation to satisfy their needs. Marketing should specifically focus on these two markets' motivations and gradually adapt marketing campaigns that these markets can consider interpretation services' use and contribute to revenue for conservation purposes. Even though they are quite small in size the park would gain additional revenue from these two segments once they are converted to either Eager or Inquisitive seekers.

\section{Conclusion}

The aim of this study was to determine market segments for the Kruger National Park based on expected interpretation services. The expected interpretation variables identified four markets or typologies labelled Inquisitive seekers, Eager seekers, Comfort seekers and Quasi-interested seekers which differed based on expected interpretation services. Two important contributions can be deduced from this study:

Even though the goal of this study was kept in mind, as might be the case with much research, there were 24 interpretation variables available with which to cluster observations. This raises a few questions such as (i) should all the variables be selected or (ii) should a factor analysis be conducted in the pre-processing of cluster analysis? Or (iii) should surrogate variables be selected and (iv) which variables should then be selected as surrogate variables? An important suggestion for future research is to base the choice of variables not only with the goal of the study in mind but to make this decision on statistical calculations as well. Researchers should compare 
the different scenarios' degree of variability and consider the assumption of multicollinearity for the best selection of variables.

This study also specifically addressed a gap in the literature by segmenting interpretation markets. This study is furthermore also the first of its kind to make use of expected interpretation as a segmentation variable for segmentation purposes which identified interpretation typologies, namely Inquisitive -, Eager -, Comfort - and Quasi-interested seekers. Ecotourism destinations, especially those who have a homogenous market similar to this study can make use of these typologies to identify different markets within their destinations, appropriately design interpretation services and ultimately manage the destination sustainably. Ecotourism destinations or products, should, however, keep tourists' motivations under advisement when assigning these typologies to markets. All four identified markets placed the highest importance on escape as a motivation to visit the park. The Comfort seekers, however, see the importance of secondary interpretation as a means to a comfortable experience since park facilities and value are their second highest motivation to visit the park and that the Quasiinterested seekers have not yet realised the importance of interpretation services to realise their special interest needs motivation (the second highest motivation to visit the park). These four typologies will most probably always be market segments for interpretation services. It is strongly recommended that this study be replicated in other ecotourism destinations and other possible interpretation destinations or products for future research to confirm the findings.

\section{References}

Ballantyne, R., Packer, J. \& Hughes, K. 2008. 'Environmental awareness, interests and motives of botanic gardens visitors: implications for interpretive practice', Tourism Management, 29(3): 439-444.

Ballantyne, R., Packer, J. \& Sutherland, L.A. 2011. 'Visitors' memories of wildlife tourism: Implications for the design of powerful interpretive experiences', Tourism Management, 32(4): 770-779.

Bartlett, M.S. 1954. 'A note on the multiplying factors for various chi square approximations', Journal of the Royal Statistical Society, 16(Series B): 296-8.

Briggs, S.R. \& Cheek, J.M. 1986. 'The role of factor analysis in the development and evaluation of personality scales', Journal of Personality, 54(1): 106-48.

Chan, J.K.L. \& Baum, T. 2007. 'Motivation factors of ecotourists in ecolodge accommodation: the push and pull factors', Asia Pacific Journal of Tourism Research, 12(4): 349-364.

Chen, H.J., Hwang, S.N. \& Lee, C. 2006. 'Visitors' characteristics of guided interpretation tours', Journal of Business Research, 59(10): 1167-1181.

Cohen, J.W. 1988. Statistical power analysis for the behavioral sciences. 2nd edition. Hillsdale, NJ: Lawrence Erlbaum Associates.
De Rojas, C. \& Camarero, C. 2008. 'Visitors' experience, mood and satisfaction in a heritage context: evidence from an interpretation centre', Tourism Management, 29(3): 525-537.

Dillon, W.R. \& Mukherjee, S. 2006. A guide to the design and execution of segmentation studies. In Grover, R. \& Vriens, M. (Eds.). The Handbook of marketing research: uses, misuses and future advances. Thousand Oaks: Sage Publications.

Dolnicar, S. 2008. Market segmentation in tourism. In Woodside, A. \& Martin, D. (Eds.). Tourism management: analysis, behaviour and strategy. Wallingford, UK; Cambridge, MA: CABI Pub.

Dolnicar, S. \& Grün, B. 2008. 'Challenging "factor-cluster segmentation", Journal of Travel Research, 47(1): 63-71.

Dolnicar, S., Grün, B., Leisch, F. \& Schmidt, K. 2014. 'Required sample sizes for data-driven market segmentation analyses in tourism', Journal of Travel Research, 53(3): 296-306.

Dolnicar, S., Kaiser, S., Lazarevski, K. \& Leisch, F. 2012. 'Biclustering: overcoming data dimensionality problems in market segmentation', Journal of Travel Research, 51(1): 41-49.

D’Urso, P., De Giovanni, L., Disegna, M. \& Massari, R. 2013. 'Bagged clustering and its application to tourism market segmentation', Expert Systems with Applications, 40(12): 49444956.

Eagles, P.F.J. 2004. Trends affecting tourism in protected areas. Policies, methods and tools for visitor management - Proceedings of the second International Conference on Monitoring and Management of visitor flows in Recreational and Protected areas. [online] URL:http://www.metla.fi/julkaisut/workingpapers/2004/ mwp002-03.

Eagles, P.F.J. 2014. 'Research priorities in park tourism', Journal of Sustainable Tourism, 22(4): 528-549.

Engelbrecht, W.H., Kruger, M \& Saayman, M. 2014. 'An analysis of critical success factors in managing the tourist experience at Kruger National Park', Tourism Review International, 17(4): 237251.

Frauman, E. 2010. 'Incorporating the concept of mindfulness in informal outdoor education settings', Journal of Experiential Education, 33(3): 225-238.

Frauman, E. \& Norman, W.C. 2004. 'Mindfulness as a tool for managing visitors to tourism destinations', Journal of Travel Research, 42(4): 381-389.

Füller, J. \& Matzler, K. 2008. 'Customer delight and market segmentation: an application of the three-factor theory of customer satisfaction on life style groups', Tourism Management, 29(1): 116126.

Getz, D. 2013. Event Tourism: concepts, international case studies, and research. USA: Cognizant Communication Corporation.

Guadagnoli, E. \& Velicer, W. 1988. 'Relation of sample size to the stability of component patterns', Psychology Bulletin, 103(2): 265275.

Hair, J.F., Black, W.C., Babin, B.J. \& Anderson, R.E. 2010. Multivariate data analysis: A global perspective. 7th edition. Upper Saddle River, N.J.; London: Pearson Education, Inc. 
Ham, S., Housego, A. \& Weiler, B. 2005. Tasmanian thematic interpretation planning manual. Tourism Tasmania, Hobart. [online] URL:http://portals.iucn.org/2012forum/sites/2012forum/ files/tourism-tas-interpretation-manual-2.pdf

Ham, S.H. \& Weiler, B. 2006. Development of a research-based tool for evaluating interpretation. Gold Coast, Qld.: CRC for Sustainable Tourism.

Ham, S.H. \& Weiler, B. 2007. 'Isolating the role of on-site interpretation in a satisfying experience', Journal of Interpretation Research, 12(2): 5-24.

Henker, K.B. \& Brown, G. 2011. 'As good as the real thing? A comparative study of interpretive podcasts and traditional ranger talks', Journal of Interpretation Research, 16(1): 7-23.

Hwang, S.N., Lee, C. \& Chen, H.J. 2005. 'The relationship among tourists' involvement, place attachment and interpretation satisfaction in Taiwan's national parks', Tourism Management, 26(2): 143-156

Jurdana, D.S. 2009. 'Specific knowledge for managing ecotourism destinations', Tourism Hospitality Management, 15(2): 267-278.

Kaiser, H. 1974. 'An index of factorial simplicity', Psychometrika, 39(1): 31-36.

Kang, M. \& Gretzel, U. 2012. 'Effects of podcast tours on tourist experiences in a national park', Tourism Management, 33(2): 440455 .

Kara, B., Deniz, B., Kilicaslan, C. \& Polat, Z. 2011. 'Evaluation of Koçarli Adnan Menderes urban forest in terms of the ecotourism', Procedia - Social and Behavioural Sciences, 19: 145-149.

Krejcie, R.B. \& Morgan, D.W. 1970. 'Determining sample size for research activities', Educational and Psychological Measurement, 30(3): 607-610.

Kruger, M., Saayman, M. \& Hermann, U. 2014. 'First-time versus repeat visitors at the Kruger National Park', Acta Commercii, 14(1): $1-9$.

Kuo, I. 2002. 'The effectiveness of environmental interpretation at resource-sensitive tourism destinations', International Journal of Tourism Research, 4(2): 87-101.

Lee, T.H. 2009. 'A structural model for examining how destination image and interpretation services affect future visitation behavior: a case study of Taiwan's Taomi eco-village', Journal of Sustainable Tourism, 17(6): 727-745.

Lee, T. \& Balchin, N. 1995. 'Learning and attitude change at British Nuclear Fuel's Sellafield visitors centre', Journal of Environmental Psychology, 15(4): 283-298.

Lee, S., Jeon, S. \& Kim, D. 2011. 'The impact of tour quality and tourist satisfaction on tourist loyalty: the case of Chinese tourists in Korea', Tourism Management, 32(5): 1115-1124.

Lee, C., Lee, J., Kim, T. \& Mjelde, J.W. 2010. 'Preferences and willingness to pay for bird-watching tour and interpretive services using a choice experiment', Journal of Sustainable Tourism, 18(5): 695-708.
Lee, C.K., Lee, J.K., Mjelde, J.W., Scott, D. \& Kim, T.K. 2009. 'Assessing the economic value of a public birdwatching interpretative service using a contingent valuation method', International Journal of Tourism Research, 11(6): 583-593.

Lucas, K.E. \& Ross, S.R. 2005. 'Zoo visitor knowledge and attitudes toward gorillas and chimpanzees', The journal of Environmental Education, 36(4): 33-48.

Madin, E.M. \& Fenton, D.M. 2004. 'Environmental interpretation in the Great Barrier Reef Marine Park: an assessment of programme effectiveness', Journal of Sustainable Tourism, 12(2): 121-137.

Malhotra, N.K. 2007. Marketing research: an applied orientation. 5th edition. Upper Saddle River, N.J.: Pearson/Prentice Hall.

Mehmetoglu, M. \& Normann, Ø. 2013. 'The link between travel motives and activities in nature-based tourism', Tourism Review, 68(2): 3-13.

Mitsche, N., Reino, S., Knox, D. \& Bauernfeind, U. 2008. Enhancing cultural tourism e-services through heritage interpretation. In O'Connor, P., Höpken, W. \& Gretzel, U. (Eds.). Information and communication technologies in tourism. Wien; New York: Springer.

Morrison, A.M. 2013. Marketing and managing tourism destinations. New York: Routledge.

National Parks Act, 57 of 1976.

Nykiel, R.A. 2007. Handbook of marketing research methodologies for hospitality and tourism. New York: Haworth Hospitality \& Tourism.

Orams, M. 1994. 'Creating effective interpretation for managing interaction between tourists and wildlife', Australian Journal of Environmental Education, 10: 21-34.

Orams, M. 1996. 'A conceptual model of tourist-wildlife interaction: the case for education as a management strategy', The Australian Geographer, 27(1): 39-51.

Pallant, J. 2011. SPSS: Survival manual. 4th edition. [online] URL:http://eunacal.org/metodakerkimi/wp-content/uploads/spss/ SPSS_Survival_Manual_4th_Edition.pdf

Peake, S., Innes, P. \& Dyer, P. 2009. 'Ecotourism and conservation: factor influencing effective conservation messages', Journal of Sustainable Tourism, 17(1): 107-127.

Periera, E. 2005. 'How do tourist guides add value to an ecotour? Interpreting interpretation in the State of Amazonas, Brazil', FIU Hospitality and Tourism Review, 23(2): 1-8.

Powell, R.B. \& Ham, S.H. 2008. 'Can ecotourism interpretation really lead to pro-conservation knowledge, attitudes and behaviour? Evidence from the Galapagos Islands', Journal of Sustainable Tourism, 16(4): 467-489.

Prentice, R. \& Anderson, V. 2007. 'Interpreting heritage essentialisms: familiarity and felt history', Tourism Management, 28(3): 661-676. 
Rabotić, B. 2010. Professional Tourist Guiding: the importance of interpretation for tourist experiences. Paper presented at the 20th Biennial International Congress: New trends in tourism and hotel management, Opatija (Croatia). [online] URL:http://rabotic.tripod.com/Branislav_Rabotic/The_Importance _of_Interpretation_for_Tourist_Experiences.pdf

Reisinger, Y. \& Steiner, C. 2006. 'Reconceptualising interpretation: the role of tour guides in authentic tourism', Current Issues in Tourism, 9(6): 481-498.

Saayman, M. 2009. Managing parks as ecotourism attractions. In Saayman, M. (Ed.). Ecotourism: getting back to basics. Potchefstroom: Leisure Consultants and Publications.

Said, A., Jaddil, N.E.F. \& Ayob, N. 2009. 'An assessment of service quality in national parks: a case study of Gunung Gading National Park, Sarawak', The Icfai University Journal of Environmental Economics, VII(2): 74-88.

Saipradist, A. \& Staiff, R. 2007. 'Crossing the cultural divide: western visitors and interpretation at Ayutthaya world heritage site, Thailand', Journal of Heritage Tourism, 2(3): 211-224.

SANParks (South African National Parks). 2012. SANParks Research Report 2012. 2 [online] URL:http://www.sanparks.org/assets/docs/conservation/reports/20 12_research_report.pdf

SANParks (South African National Parks). 2013. Annual Report 2012/2013. [online] URL:http://www.sanparks.co.za/assets/docs/ general/annual-report-2013.pdf

SANParks (South African National Parks). 2014. Annual report 2013/2014. [online] URL:www.sanparks.co.za/assets/docs/ general/annual-report-2014.pdf

Schiffman, L.G. \& Kanuk, L.L. 2004. Consumer behaviour. 8th edition. Upper Saddle River, N.J.: Prentice Hall.

Schmidt, M.J. \& Hollensen, S. 2006. Marketing research: an international approach. Harlow, England; New York: Prentice Hall/Financial Times.

Sharma, S. \& Kumar, A. 2006. Cluster analysis and factor analysis. In Grover, R. \& Vriens, M. (Eds.). The Handbook of Marketing Research: uses, misuses and future advances. Thousand Oaks: Sage Publications.

Shultis, J.D. \& Way, P.A. 2006. 'Changing conceptions of protected areas and conservation: linking conservation, ecological integrity and tourism management', Journal of Sustainable Tourism, 14(3): 223-237.

SPSS. 2013. IBM SPSS computer software (Version 22). Chicago, IBM.

Stevens, J.P. 2009. Applied multivariate statistics for the social sciences. 5th edition. New York: Routledge.

Stewart, E.J., Hayward, B.M., Devlin, P.J. \& Kirby, V.G. 1998. 'The "place" of interpretation: a new approach to the evaluation of interpretation', Tourism Management, 19(3): 257-266.

Steyn, H.S. 2000. 'Practical significance of the difference in means', South African Journal of Industrial Psychology, 26(3): 1-3. [online] URL:http://reference.sabinet.co.za/sa_epublication_article/ psyc_v26_n3_a1

Tilden, F. 1977. Interpreting our heritage. 3rd edition. Chapel Hill: University of North Carolina Press.

Ward, C.W. \& Wilkinson, A.E. 2006. Conducting meaningful interpretation: a field guide for success. Golden Colo.: Fulcrum Publishing.

Wearing, S. \& Neil, J. 2009. Ecotourism impacts, potentials and possibilities. 2nd edition. Oxford: Butterworth-Heinemann.

Zeppel, H. \& Muloin, S. 2008. 'Conservation benefits of interpretation on marine wildlife tours', Human Dimensions of Wildlife, 13(4): 280-294.

Zikmund, W.G., Babin, B.J., Carr, J.C. \& Griffin, M. 2010. Business research Methods. 8th edition. Mason, OH: South Western Cencage Learning. 